\title{
Pathophysiology of asthma
}

\section{PETER J. BARNES}

Department of Thoracic Medicine, National Heart and Lung Institute, Imperial College, London, UK

1 Our understanding of asthma and its therapy has changed markedly over the last few years, particularly with the application of molecular and cell biology and the discovery of new and more specific pharmacological tools.

2 Many inflammatory cells participate in the inflammatory process in asthma and mediate a complex mixture of mediators. Cytokines are of particular importance as mediators of chronic inflammation and the means by which cytokines amplify and perpetuate the inflammatory process is now emerging. Airway epithelial cells may be a particularly important source of cytokines and other mediators, such as nitric oxide and endothelin, and may be a major target cell for inhaled steroids, which are the most effective therapy for asthma currently available.

3 The inflammatory process in asthma results not only in bronchoconstriction, but also plasma exudation, the activation of neural mechanisms, mucus secretion. The chronic inflammation may lead to structural changes, including an increase in airway smooth muscle and fibrosis, that are essentially irreversible. There is increasing evidence that transcription factors, such as $\mathrm{NF}-\mathrm{\kappa B}$, play a pivotal role in the expression of inflammatory genes in asthma and may be the major molecular target for glucocorticoids.

Keywords asthma inflammation inflammatory mediators eosinophils T-lymphocytes epithelial cells neuropeptides transcription factors

\begin{abstract}
Introduction
Asthma is one of the commonest diseases in industrialized countries and there is convincing evidence to suggest that its prevalence and morbidity are increasing, despite better recognition and increased prescriptions for anti-asthma therapy. It is somewhat paradoxical that the morbidity and mortality of asthma should be increasing at a time when there is increased understanding of the pathophysiology of asthma and when effective therapies are available; it points to the need for even better understanding of the underlying mechanisms involved in asthma and elucidation of the mode of action of currently available anti-asthma therapies. Clinical pharmacology has made important contributions to our understanding of asthma, since drugs such as mediator antagonists have elucidated the underlying inflammatory mechanisms and the drugs
\end{abstract}

used to treat asthma have provided important insights into disease mechanisms. Colin Dollery has made important contributions to this field in pioneering the clinical pharmacology approach, leading to greater understanding of adrenergic and neural mechanisms of asthma and the role of inflammatory mediators, such as leukotrienes and prostaglandins.

Our views on asthma have changed in the last decade, with the recognition that chronic inflammation underlies the clinical syndrome. In the past it was assumed that the basic defect in asthma lay in abnormal contractility of airway smooth muscle, giving rise to variable airflow obstruction, and the common symptoms of intermittent wheeze and shortness of breath. However studies of airway smooth muscle from asthmatic patients have shown no convincing evidence for increased contractile responses to spasmogens such as histamine in vitro, indicating that asthmatic airway smooth muscle is not

Correspondence: Professor P. J. Barnes, Department of Thoracic Medicine, National Heart and Lung Institute, Imperial College, Dovehouse Street, London SW3 6LY, UK 
fundamentally abnormal and suggesting that it is the control of airway calibre in vivo which is abnormal.

For many years it has been assumed that mast cells play a critical role in asthma and that mast cell mediators produce the pathophysiology of asthma. More recently it has become clear that many different inflammatory cells are activated in asthmatic airways, and that these cells produce a variety of mediators which act in a complex manner on target cells of the airways to produce the abnormal pathophysiological features typical of asthma. Recent research has established that asthma, even in its mildest clinical forms, involves a special type of inflammation in the airways.

\section{Asthma as an inflammatory disease}

It had been recognised for many years that patients who die of asthma attacks have grossly inflamed airways. The airway lumen is occluded by a tenacious mucus plug composed of plasma proteins exuded from airway vessels and mucus glycoproteins secreted from surface epithelial cells. The airway wall is oedematous and infiltrated with inflammatory cells, which are predominantly eosinophils and lymphocytes. The airway epithelium is invariably shed in a patchy manner and clumps of epithelial cells are found in the airway lumen. Occasionally there have been opportunities to examine the airways of asthmatic patients who die accidentally and similar though less marked inflammatory changes have been observed [1]. More recently it has been possible to examine the airways of asthmatic patients by fibreoptic and rigid bronchoscopy, by bronchial biopsy and by bronchoalveolar lavage (BAL). Direct bronchoscopy reveals that the airways of asthmatic patients are often reddened and swollen, indicating acute inflammation. Lavage has revealed an increase in the numbers of lymphocytes, mast cells and eosinophils and evidence for activation of macrophages in comparison with non-asthmatic controls. Biopsies have revealed evidence for increased numbers and activation of mast cells, macrophages, eosinophils and T-lymphocytes [2]. These changes are found even in patients with mild asthma who have few symptoms, and this suggests that asthma is an inflammatory condition of the airways.

The relationship between inflammation and clinical symptoms of asthma is not clear. There is evidence that the degree of inflammation is related to airway hyperresponsiveness (AHR), as measured by histamine or methacholine challenge. Increased airway responsiveness is an exaggerated airway narrowing in response to many stimuli which is characteristic of asthma and the degree of AHR relates to asthma symptoms. Inflammation of the airways may increase airway responsiveness which thereby allows triggers which would not narrow the airways to do so. But inflammation may also directly lead to an increase in asthma symptoms, such as cough and chest tightness, by activation of airway sensory nerve endings.

Although most attention has been focused on the acute inflammatory changes seen in asthmatic airways, asthma is a chronic inflammatory disease, with inflammation persisting over many years in most patients. Superimposed on this chronic inflammatory state are acute inflammatory episodes which correspond to exacerbations of asthma. It is clearly important to understand the mechanisms of acute and chronic inflammation in asthmatic airways and to investigate the long-term consequences of this chronic inflammation on airway function. It is also important to consider the effects of therapy on the inflammatory process.

\section{Inflammatory cells}

Many different inflammatory cells are involved in asthma, although the precise role of each cell type is not yet certain $[3,4]$. It is evident that no single inflammatory cell is able to account for the complex pathophysiology of asthma, but some cells are predominant in asthmatic inflammation.

Mast cells are clearly important in initiating the acute responses to allergen and probably to other indirect stimuli, such as exercise and hyperventilation (via osmolality or thermal changes) and fog. However there are questions about the role of mast cells in more chronic inflammatory events, and it seems more probable that other cells such as macrophages, eosinophils and T-lymphocytes are more important in the chronic inflammatory process, including AHR.

Macrophages, which are derived from blood monocytes, may traffic into the airways in asthma and may be activated by allergen via low affinity $\operatorname{IgE}$ receptors [5]. The enormous repertoire of macrophages allows these cells to produce many different products, including a large variety of cytokines which may orchestrate the inflammatory response. Macrophages therefore have the capacity to initiate a particular type of inflammatory response via the release of a certain pattern of cytokines. Macrophages may both increase and decrease inflammation, depending on the stimulus. Alveolar macrophages normally have a suppressive effect on lymphocyte function, but this may be impaired in asthma after allergen exposure [6]. Macrophages may therefore play an important anti-inflammatory role, preventing the development of allergic inflammation. Macrophages may also act as antigen-presenting cells which process allergen for presentation to T-lymphocytes, although alveolar macrophages are far less effective in this respect than macrophages from other sites, such as the peritoneum [7]. By contrast dendritic cells which are specialised macrophage-like cells in the airway epithelium, are very effective antigen-presenting cells [7], and may therefore play a very important role in the initiation of allergen-induced responses in asthma.

Eosinophil infiltration is a characteristic feature of asthmatic airways and differentiates asthma from other inflammatory conditions of the airway. Indeed, asthma might more accurately be termed 'chronic eosinophilic bronchitis' (a term first used in 1916!). Allergen inhalation results in a marked increase in eosinophils in bronchoalveolar lavage fluid at the time of the late reaction, and 
there is a close relationship between eosinophil counts in peripheral blood or bronchial lavage and AHR. Eosinophils were originally viewed as beneficial cells in asthma, as they have the capacity to inactivate histamine and leukotrienes, but it now seems more likely that they may play a damaging role, and may be linked to the development of airway hyperresponsiveness through the release of basic proteins and oxygen-derived freeradicals [8].

An important area of research is now concerned with the mechanisms involved in recruitment of eosinophils into asthmatic airways. Eosinophils are derived from bone marrow precursors. After allergen challenge eosinophils appear in BAL fluid during the late response, and this is associated with a decrease in peripheral eosinophil counts and with the appearance of eosinophil progenitors in the circulation. The signal for increased eosinophil production is presumably derived from the inflamed airway. Eosinophil recruitment initially involves adhesion of eosinophils to vascular endothelial cells in the airway circulation, their migration into the submucosa and their subsequent activation. The role of individual adhesion molecules, cytokines and mediators in orchestrating these responses has yet to be clarified. Adhesion of eosinophils involves the expression of specific glycoprotein molecules on the surface of eosinophils (integrins) and their expression of such molecules as intercellular adhesion molecule-1 (ICAM-1) on vascular endothelial cells. An antibody directed at ICAM-1 markedly inhibits eosinophil accumulation in the airways after allergen exposure and also blocks the accompanying hyperresponsiveness [9]. However ICAM-1 is not selective for eosinophils and cannot account for the selective recruitment of eosinophils in allergic inflammation. The adhesion molecules VLA4 expressed on eosinophils and vascular cell adhesion molecule-1 (VCAM-1) appear to be more selective for eosinophils [10] and interleukin-4 (IL-4) increases the expression of VCAM-1 on endothelial cells [11]. Eosinophil migration may be due to the effects of platelet anticoating factor (PAF), which is selectively chemoattractant to eosinophils [12], and to the effects of cytokines such as GM-CSF, IL-3 and IL-5 [13]. These cytokines may be very important for the survival of eosinophils in the airways and may 'prime' eosinophils to exhibit enhanced responsiveness. Eosinophils from asthmatic patients show greatly exaggerated responses to PAF and phorbol esters, than eosinophils from atopic non-asthmatic individuals [14] and this is further increased by allergen challenge [15], suggesting that they may have been primed by exposure to cytokines in the circulation. There are several mediators involved in the migration of eosinophils from the circulation to the surface of the airway. The most potent and selective agents appear to be chemokines, such as RANTES, that is expressed in epithelial cells [16], and eotaxin [17].

The role of neutrophils in human asthma is less clear. Neutrophils are found in the airways of chronic bronchitics and patients with bronchiectasis who do not have the degree of AHR found in asthma, but there is increasing evidence that neutrophils may be important in acute exacerbations of asthma.
T-lymphocytes play a very important role in co-ordinating the inflammatory response in asthma through the release of specific patterns of cytokines, resulting in the recruitment and survival of eosinophils and in the maintenance of mast cells in the airways. T-lymphocytes are coded to express a distinctive pattern of cytokines, which may be similar to that described in the murine Th2 type of T-lymphocytes, which characteristically expresses IL-3, IL-4 and IL-5 [18]. This programming of T-lymphocytes is presumably due to antigen presenting cells such as dendritic cells, which may migrate from the epithelium to regional lymph nodes or which interact with lymphocytes resident in the airway mucosa.

\section{Epithelial cells}

Epithelial cells also produce inflammatory mediators, such as endothelins, proinflammatory cytokines, chemokines and growth factors [19]. Epithelial cells may play a key role in translating inhaled environmental signals into an airway inflammatory response and are probably the main target cell for inhaled glucocorticoids.

\section{Inflammatory mediators}

Many different mediators have been implicated in asthma and they may have a variety of effects on the airways which could account for the pathological features of asthma [20, 21]. Mediators such as histamine, prostaglandins and leukotrienes contract airway smooth muscle, increase microvascular leakage, increase airway mucus secretion and attract other inflammatory cells. Because each mediator has many effects the role of individual mediators in the pathophysiology of asthma is not yet clear. Indeed the multiplicity of mediators makes it unlikely that antagonising a single mediator will have a major impact in clinical asthma.

The cysteinyl-leukotrienes $\mathrm{LTC}_{4}, \mathrm{LTD}_{4}$ and $\mathrm{LTE}_{4}$ are potent constrictors of human airways and have been reported to increase AHR and may play an important role in asthma [22]. The recent development of potent specific leukotriene antagonists has made it possible to evaluate the role of these mediators in asthma. Potent $\mathrm{LTD}_{4}$ antagonists protect (by about 50\%) against exercise- [23] and allergen-induced bronchoconstriction [24], suggesting that leukotrienes contribute to bronchoconstrictor responses. Chronic treatment with leukotriene antagonists improve lung function and symptoms in asthmatic patients, although the degree of improvement is modest compared with what would be expected of an inhaled glucocorticoid [25]. The role of leukotrienes in chronic asthma remains to be defined and several clinical trials with potent antagonists are currently underway.

A mediator which has attracted considerable attention recently is PAF, since it mimics many of the features of 
asthma, including AHR [12]. Although PAF appears to be produced by the inflammatory cells involved in asthmatic inflammation and mimics many of the pathophysiological features of asthma, its role in asthma will only become apparent with the use of potent and specific antagonists. Initial results with potent PAF antagonists such as apafant (WEB 2086) and modipafant in chronic asthma have been disappointing, however $[26,27]$.

\section{Cytokines}

Cytokines are increasingly recognised to be important in chronic inflammation and play a critical role in orchestrating the type of inflammatory response. Many inflammatory cells (macrophages, mast cells, eosinophils and lymphocytes) are capable of synthesising and releasing these proteins, and structural cells such as epithelial cells and endothelial cells may also release a variety of cytokines and may therefore participate in the chronic inflammatory response [13]. While inflammatory mediators like histamine and leukotrienes may be important in the acute and subacute inflammatory responses and in exacerbations of asthma, it is likely that cytokines play a dominant role in chronic inflammation. Almost every cell is capable of producing cytokines under certain conditions. Research in this area is hampered by a lack of specific antagonists, although important observations have been made using specific neutralising antibodies. The cytokines which appear to be of particular importance in asthma include the lymphokines secreted by T-lymphocytes: IL-3, which is important for the survival of mast cells in tissues, IL-4 which is critical in switching B-lymphocytes to produce $\mathrm{IgE}$ and for expression of VCAM-1 on endothelial cells, IL-5 which is of critical importance in the differentiation, survival and priming of eosinophils. There is evidence for increased gene expression of IL-5 in lymphocytes in bronchial biopsies of patients with symptomatic asthma [28]. Other cytokines, such as IL-1, IL-6, tumour necrosis factor- $\alpha(\mathrm{TNF}-\alpha)$ and GM-CSF are released from a variety of cells, including macrophages and epithelial cells, and may be important in amplifying the inflammatory response. TNF- $\alpha$ may be an important amplifying mediator in asthma and is produced in increased amounts in asthmatic airways. Inhalation of $\mathrm{TNF}-\alpha$ increased airway responsiveness in normal individuals [29].

\section{Endothelins}

Endothelins are potent peptide mediators that are potent vasoconstrictors and bronchoconstrictors [30]. They also induce airway smooth muscle cell proliferation and fibrosis and may therefore play a role in the chronic inflammation of asthma. There is evidence for increased expression of endothelins in asthma, particularly in airway epithelial cells [31].
Nitric oxide

Nitric oxide (NO) is produced by several cells in the airway by NO synthases (NOS) [32]. An inducible form of the enzyme (iNOS) is expressed in epithelial cells of asthmatic patients [33] and can be induced by cytokines in airway epithelial cells [34]. This may account for the increased concentration of NO in the exhaled air of asthmatic patients [35]. NO itself is a potent vasodilator and this may increase plasma exudation in the airways; it may also amplify the Th2-lymphocyte mediated response [36].

\section{Effects of inflammation}

The chronic inflammatory response has several effects on the target cells of the airways, resulting in the characteristic pathophysiological changes associated with asthma. Important advances have recently been made in understanding these changes, although their role in asthma symptoms is often not clear.

\section{Airway epithelium}

Airway epithelial shedding may be important in contributing to airway hyperresponsiveness and may explain how several different mechanisms, such as ozone exposure, certain virus infections, chemical sensitisers and allergen exposure, can lead to its development, since all these stimuli may lead to epithelial disruption. Epithelium may be shed as a consequence of inflammatory mediators, such as eosinophil basic proteins and oxygen-derived free radicals, together with various proteases released from inflammatory cells. Epithelial cells are commonly found in clumps in the BAL or sputum (Creola bodies) of asthmatics, suggesting that there has been a loss of attachment to the basal layer or basement membrane. Epithelial damage may contribute to AHR in a number of ways, including loss of its barrier function to allow penetration of allergens, loss of enzymes (such as neutral endopeptidase) which normally degrade inflammatory mediators, loss of a relaxant factor (so called epithelial-derived relaxant factor), and exposure of sensory nerves which may lead to reflex neural effects on the airway.

\section{Subepithelial fibrosis}

An apparent increase in the basement membrane has been described in fatal asthma, although similar changes have been described in the airways in other conditions [1]. Electron microscopy of bronchial biopsies in asthmatic patients demonstrates that this thickening is due to subepithelial fibrosis [2]. Type III and V collagen appear to be laid down, and may be produced by myofibroblasts which are situated under the epithelium. The mechanism of fibrosis is not yet clear but several cytokines, including TGF $\beta$ and platelet derived growth 
factor (PDGF) may be produced by epithelial cells or macrophages in the inflamed airway [13].

\section{Airway smooth muscle}

There is still debate about the role of abnormalities in airway smooth muscle in asthmatic airways. In vitro airway smooth muscle from asthmatic patients usually shows no increased responsiveness to spasmogens. Reduced responsiveness to $\beta$-adrenoceptor agonists has also been reported in post-mortem or surgically removed bronchi from asthmatics, although the number of $\beta$-receptors is not reduced, suggesting that $\beta$-receptors have been uncoupled [37]. These abnormalities of airway smooth muscle may be a reflection of the chronic inflammatory process. For example the reduced $\beta$-adrenergic responses in airway smooth muscle could be due to phosphorylation of the stimulatory G-protein coupling $\beta$-receptors to adenylyl cyclase, resulting from the activation of protein kinase $\mathrm{C}$ by the stimulation of airway smooth muscle cells by inflammatory mediators [38].

In asthmatic airways there is also a characteristic hypertrophy and hyperplasia of airway smooth muscle [39], which is presumably the result of stimulation of airway smooth muscle cells by various growth factors, such as PDGF, or endothelin-1 released from inflammatory cells.

\section{Vascular responses}

Vasodilatation occurs in inflammation, yet little is known about the role of the airway circulation in asthma, partly because of the difficulties involved in measuring airway blood flow. The bronchial circulation may play an important role in regulating airway calibre, since an increase in the vascular volume may contribute to airway narrowing. Increased airway blood flow may be important in removing inflammatory mediators from the airway, and may play a role in the development of exercise-induced asthma.

\section{Plasma extravasation}

Microvascular leakage is an essential component of the inflammatory response and many of the inflammatory mediators implicated in asthma produce this leakage $[20,40,41]$. There is good evidence for microvascular leakage in asthma and it may have several consequences on airway function, including increased airway secretions, impaired mucociliary clearance, formation of new mediators from plasma precursors (such as kinins) and mucosal oedema which may contribute to airway narrowing and increased airway hyperresponsiveness.

\section{Mucus hypersecretion}

Mucus hypersecretion is a common inflammatory response in secretory tissues. Increased mucus secretion contributes to the viscid mucus plugs which occlude asthmatic airways, particularly in fatal asthma. There is evidence for hyperplasia of submucosal glands which are confined to large airways and of increased numbers of epithelial goblet cells. This increased secretory response may be due to inflammatory mediators acting on submucosal glands and due to stimulation of neural elements. Little is understood about the control of goblet cells, which are the main source of mucus in peripheral airways, although recent studies investigating the control of goblet cells in guinea pig airways suggest that cholinergic, adrenergic and sensory neuropeptides are important in stimulating secretion [42].

\section{Neural effects}

There has recently been a revival of interest in neural mechanisms in asthma [43]. Autonomic nervous control of the airways is complex, for in addition to classical cholinergic and adrenergic mechanisms, non-adrenergic non-cholinergic (NANC) nerves and several neuropeptides have been identified in the respiratory tract [44]. Several studies have investigated the possibility that defects in autonomic control may contribute to airway hyperresponsiveness and asthma, and abnormalities of autonomic function, such as enhanced cholinergic and $\alpha$ adrenergic responses or reduced $\beta$-adrenergic responses, have been proposed. Current thinking suggests that these abnormalities are likely to be secondary to the disease, rather than primary defects [43]. It is possible that airway inflammation may interact with autonomic control by several mechanisms.

Inflammatory mediators may act on various pre-junctional receptors on airway nerves to modulate the release of neurotransmitters [45]. Thus thromboxane and prostaglandin $\mathrm{D}_{2}\left(\mathrm{PGD}_{2}\right)$ facilitate the release of acetylcholine from cholinergic nerves in canine airways, whereas histamine inhibits cholinergic neurotransmission at both parasympathetic ganglia and post-ganglionic nerves via $\mathrm{H}_{3}$-receptors. Inflammatory mediators may also activate sensory nerves, resulting in reflex cholinergic bronchoconstriction or release of inflammatory neuropeptides. Inflammatory products may also sensitise sensory nerve endings in the airway epithelium, so that the nerves become hyperalgesic. Hyperalgesia and pain (dolor) are cardinal signs of inflammation, and in the asthmatic airway may mediate cough and dyspnoea, which are such characteristic symptoms of asthma. The precise mechanisms of hyperalgesia are not yet certain, but mediators such as prostaglandins and certain cytokines may be important.

Bronchodilator nerves which are non-adrenergic are prominent in human airways, and it has been suggested that these nerves may be defective in asthma [46]. In animal airways vasoactive intestinal peptide (VIP) has been shown to be a neurotransmitter of these nerves and a striking absence of VIP-immunoreactive nerves has been reported in the lungs from patients with severe fatal asthma [47]. However it is likely that this loss of 
VIP immunoreactivity is due to degradation by tryptase released from degranulating mast cells in the airways of asthmatics [48]. In human airways the bronchodilator neurotransmitter appears to be NO [49].

Airway nerves may also release neurotransmitters which have inflammatory effects. Thus neuropeptides such as substance $\mathrm{P}(\mathrm{SP})$, neurokinin A and calcitoningene related peptide may be released from sensitised inflammatory nerves in the airways which increase and extend the ongoing inflammatory response [50]. There is evidence for an increase in SP-immunoreactive nerves in airways of patients with severe asthma [51], which may be due to proliferation of sensory nerves and increased synthesis of sensory neuropeptides as a result of nerve growth factors released during chronic inflammation. There may also be a reduction in the activity of enzymes, such as neutral endopeptidase, which degrade neuropeptides such as SP [52]. There is also evidence for increased gene expression of the receptor which mediates the inflammatory effects of SP [53]. Thus chronic asthma may be associated with increased neurogenic inflammation, which may provide a mechanism for perpetuating the inflammatory response even in the absence of initiating inflammatory stimuli.

\section{Transcription factors}

The chronic inflammation of asthma is due to increased expression of multiple inflammatory proteins (MIP: cytokines, enzymes, receptors, adhesion molecules). In many cases these inflammatory proteins are induced by transcription factors, DNA binding factors that increase the transcription of selected target genes [54]. One transcription factor that may play a critical role in asthma is nuclear factor-kappa $\mathrm{B}(\mathrm{NF}-\mathrm{kB})$ which can be activated by multiple stimuli, including protein kinase $\mathrm{C}$ activators, oxidants and proinflammatory cytokines (such as IL-1 $\beta$ and TNF- $\alpha$ ). NF- $\kappa$ B is the predominant transcription regulating the expression of iNOS, the inducible form of cyclooxygenase (COX-2), chemokines (IL-8, RANTES, MIP-1 $\alpha$ ), proinflammatory cytokines (TNF- $\alpha$, GM-CSF) and adhesion molecules (ICAM-1, VCAM-1) [55]. NF- $\mathrm{KB}$ in epithelial cells may play a pivotal role in amplifying inflammation in diseases such as asthma [56]. This is further supported by studies showing that NF- $\mathrm{KB}$ is potently inhibited by glucocorticoids [57].

\section{Implications for therapy}

The advances in our understanding of asthma have important implications for the way in which asthma therapy should be used. In the past asthma was treated primarily with bronchodilators, which act predominantly by relaxing airway smooth muscle. However since it is now apparent that even the mildest of asthmatic patients have airway inflammation which leads to airway narrowing it would seem more appropriate to use anti-inflammatory treatment as first-line therapy [58]. For patients with mild asthma sodium cromoglycate or nedocromil sodium may be sufficient, but for many patients with asthma inhaled corticosteroids will be needed. Inhaled glucocorticoids are highly effective in controlling asthma and may work on many aspects of the chronic inflammatory response [59]. By contrast bronchodilators, such as $\beta_{2}$-adrenoceptor agonists, may relieve the symptoms of asthma acutely, but fail to control the underlying chronic inflammatory response. Indeed there is evidence to suggest that regular use of inhaled $\beta_{2}$-adrenoceptor agonists may even increase AHR and chronic asthma symptoms [60]. It is now recommended that they should be used only for acute symptom control and that asthma should be controlled primarily with inhaled anti-inflammatory agents. It is hoped that the earlier use of inhaled steroids may reduce the morbidity and mortality of asthma and may also prevent the irreversible structural changes which may underlie the gradual decline in lung function seen in patients with poorly controlled asthma and there is some evidence to support this [61].

\section{References}

1 Dunnill MS. The pathology of asthma, with special reference to the changes in the bronchial mucosa. J Clin Pathol 1960; 13: 27-33.

2 Djukanovic R, Roche UR, Wilson JW, et al. Mucosal inflammation in asthma. Am Rev Respir Dis 1990; 142: 434-457.

3 Barnes PJ. New concepts in the pathogenesis of bronchial hyperresponsiveness and asthma. J Allergy Clin Immunol 1989; 83: 1013-1026.

4 Barnes PJ. New aspects of asthma. J Int Med 1992; 231: 453-461.

5 Lee TM, Lane SJ. The role of macrophages in the mechanisms of airway inflammation in asthma. Am Rev Respir Dis 1992; 145: S27-30.

6 Spiteri MA, Knight RA, Jeremy JY, Barnes PJ, Chung KF. Alveolar macrophage-induced suppression of peripheral blood mononuclear cell responsiveness is reversed by in vitro allergen exposure in bronchial asthma. Eur Resp J 1994; 7: 1431-1438.

7 Holt PG. Regulation of antigen-presenting cell function(s) in lung and airway tissues. Eur Respir J 1993; 6: 120-129.

8 Gleich GJ. The eosinophil and bronchial asthma: current understanding. J Allergy Clin Immunol 1990; 85: 422-436.

9 Wegner CD, Gundel L, Reilly P, Haynes N, Letts LG, Rothlein R. Intracellular adhesion molecule-1 (ICAM-1) in the pathogenesis of asthma. Science 1990; 247: 456-459.

10 Pilewski JM, Albelda SM. Cell adhesion molecules in asthma: homing, activation and airway remodelling. Am J Respir Cell Mol Biol 1995; 12: 1-3.

11 Lamas AM, Mulroney CM, Schleimer RP. Studies of the adhesive interaction between purified human eosinophils and cultured vascular endothelial cells. J Immunol 1988; 140: $1500-1510$.

12 Barnes PJ, Chung KF, Page CP. Platelet-activating factor as a mediator of allergic disease. J Allergy Clin Immunol 1988; 81: 919-934. 
13 Barnes PJ. Cytokines as mediators of chronic asthma. Am J Resp Crit Care Med 1994; 150: S42-S49.

14 Chanez P, Dent G, Yukawa T, Barnes PJ, Chung KF. Generation of oxygen free radicals from blood eosinophils from asthma patients after stimulation with PAF or phorbol ester. Eur Respir J 1990; 3: 1002-1007.

15 Evans DJ, Lindsay MA, O’Connor BJ, Barnes PJ. Priming of circulating human eosinophils following exposure to allergen challenge. Eur Respir J 1996; (in press).

16 Kwon OJ, Jose PJ, Robbins RA, Schall TJ, Williams TJ, Barnes PJ. Glucocorticoid inhibition of RANTES expression in human lung epithelial cells. Am J Respir Cell Mol Biol 1995; 12: 488-496.

17 Jose PJ, Griffiths-Johnson DA, Collins PD, et al. Eotaxin: a potent eosinophil chemoattractant cytokine detected in a guinea pig model of allergic airways inflammation. $J$ Exp Med 1994; 179: 881-887.

18 Kay AB. Asthma and inflammation. J Allergy Clin Immunol 1991; 87: 893-913.

19 Devalia JL, Davies RJ. Airway epithelial cells and mediators of inflammation. Resp Med 1993; 6: 405-408.

20 Barnes PJ, Chung KF, Page CP. Inflammatory mediators and asthma. Pharmacol Rev 1988; 40: 49-84.

21 Barnes PJ, Chung KF, Page CP. Inflammatory mediators and asthma. Pharmacol Rev 1996; (in press).

22 Arm JP, Lee TH. Sulphidopeptide leukotrienes in asthma. Clin Sci 1993; 84: 501-510.

23 Manning PJ, Watson RM, Margolskee, Williams VC, Schwartz JI, O’Byrne PM. Inhibition of exercise-induced bronchoconstriction by MK-571, a potent leukotriene $\mathrm{D}_{4^{-}}$ receptor antagonist. New Engl J Med 1990; 323: 1736-1739.

24 Taylor IK, O'Shaughnessy KM, Fuller RW, Dollery CT. Effect of cysteinyl-leukotriene receptor antagonist ICI 204,219 on allergen-induced bronchoconstriction and airway hyperreactivity in atopic subjects. Lancet 1991; 337: 690-694.

25 Spector SL, Smith LJ, Glass M. Effects of 6 weeks of therapy with oral doses of ICI 204,219, a leukotriene $\mathrm{D}_{4}$ receptor antagonist in subjects with bronchial asthma. $\mathrm{Am}$ J Resp Crit Care Med 1994; 150: 618-623.

26 Spence DPS, Johnston SL, Calverley PMA, et al. The effect of the orally active platelet-activating factor antagonist WEB 2086 in the treatment of asthma. Am J Resp Crit Care Med 1994; 149: 1142-1148.

27 Kuitert LM, Angus RM, Barnes NC, et al. The effect of a novel potent PAF antagonist, modipafant, in chronic asthma. Am J Respir Crit Care Med 1995; 151: 1331-1335.

28 Hamid Q, Azzawi M, Sun Ying, et al. Expression of mRNA for interleukin-5 in mucosal bronchial biopsies from asthma. J Clin Invest 1991; 87: 1541-1549.

29 Thomas PS, Yates DH, Barnes PJ. Tumor necrosis factora increases airway responsiveness and sputum neutrophils in normal human subjects. Am J Respir Crit Care Med 1995; 152: 76-80

30 Barnes PJ. Endothelins and pulmonary diseases. J Appl Physiol 1994; 77: 1051-1059.

31 Springall DR, Howarth PH, Counihan H, Djukanovic R, Holgate ST, Polak JM. Endothelin immunoreactivity of airway epithelium in asthmatic patients. Lancet 1991; 337: 697-701.

32 Barnes PJ. Nitric oxide and airway disease. Ann Med 1995; 27: 91-97.

33 Hamid Q, Springall DR, Riveros-Moreno V, et al. Induction of nitric oxide synthase in asthma. Lancet 1993 342: 1510-1513.

34 Robbins RA, Barnes PJ, Springall DR, et al. Expression of inducible nitric oxide synthase in human bronchial epi- thelial cells. Biochem Biophys Res Commun 1994; 203 : 209-218.

35 Kharitonov SA, Yates D, Robbins RA, Logan-Sinclair R, Shinebourne E, Barnes PJ. Increased nitric oxide in exhaled air of asthmatic patients. Lancet 1994; 343: 133-135.

36 Barnes PJ, Liew FY. Nitric oxide and asthmatic inflammation. Immunol Today 1995; 16: 128-130.

37 Bai TR, Mak JCW, Barnes PJ. A comparison of betaadrenergic receptors and in vitro relaxant responses to isoproterenol in asthmatic airway smooth muscle. $A m$ J Respir Cell Mol Biol 1992; 6: 647-651.

38 Grandordy BM, Mak JCW, Barnes PJ. Modulation of airway smooth muscle b-adrenoceptor function by a muscarinic agonist. Life Sci 1994; 54: 185-191.

39 Ebina M, Yaegashi H, Chiba R, Takahashi T, Motomiya M, Tanemura M. Hyperreactive site in the airway tree of asthmatic patients recoded by thickening of bronchial muscles: a morphometric study. Am Rev Respir Dis 1990; 141: 1327-1332.

40 Persson CGA. Plasma exudation and asthma. Lung 1988; 166: $1-23$.

41 Chung KF, Rogers DF, Barnes PJ, Evans TW. The role of increased airway microvascular permeability and plasma exudation in asthma. Eur Respir J 1990; 3: 329-337.

42 Kuo H, Rhode JAL, Tokuyama K, Barnes PJ, Rogers DF. Capsaicin and sensory neuropeptide stimulation of goblet cell secretion in guinea pig trachea. $J$ Physiol 1990; 431: 629-641.

43 Barnes PJ. Is asthma a nervous disease? The Parker B Francis Lecture. Chest 1995; 107: 119S-124S.

44 Barnes PJ, Baraniuk J, Belvisi MG. Neuropeptides in the respiratory tract. Am Rev Respir Dis 1991; 144: 1187-1198, 1391-1399.

45 Barnes PJ. Modulation of neurotransmission in airways. Physiol Rev 1992; 72: 699-729.

46 Lammers JWJ, Barnes PJ, Chung KF. Non-adrenergic, non-cholinergic airway inhibitory nerves. Eur Respir $J$ 1992; 5: 239-246.

47 Ollerenshaw S, Jarvis D, Woolcock A, Sullivan C, Scheibner T. Absence of immunoreactive vasoactive intestinal polypeptide in tissue from the lungs of patients with asthma. N Engl J Med 1989; 320: 1244-1248.

48 Barnes PJ. Vasoactive intestinal peptide and asthma. $N$ Engl J Med 1989; 321: 1128-1129.

49 Belvisi MG, Stretton CD, Barnes PJ. Nitric oxide is the endogenous neurotransmitter of bronchodilator nerves in human airways. Eur J Pharmacol 1992; 210: 221-222.

50 Barnes PJ. Sensory nerves, neuropeptides and asthma. Ann NY Acad Sci 1991; 629: 359-370.

51 Ollerenshaw SL, Jarvis D, Sullivan CE, Woolcock AJ. Substance $\mathrm{P}$ immunoreactive nerves in airways from asthmatics and non-asthmatics. Eur Respir J 1991; 4: 673-682.

52 Nadel JA. Neutral endopeptidase modulates neurogenic inflammation. Eur Respir J 1991; 4: 745-754.

53 Adcock IM, Peters M, Gelder C, Shirasaki H, Brown CR, Barnes PJ. Increased tachykinin receptor gene expression in asthmatic lung and its modulation by steroids. $J \mathrm{Mol}$ Endocrinol 1993; 11: 1-7.

54 Barnes PJ, Adcock IM. Transcription factors in asthma. Clin Exp Allergy 1995; 27 (Suppl 2): 46-49.

55 Siebenlist U, Franzuso G, Brown R. Structure, regulation and function of NF-кB. Ann Rev Cell Biol 1994; 10: 405-455.

56 Barnes PJ, Karin M. NF-kappa B: pivotal role in chronic inflammation. $N$ Engl J Med 1996; (in press).

57 Barnes PJ, Adcock IM. Anti-inflammatory actions of

(C) 1996 Blackwell Science Ltd British Journal of Clinical Pharmacology 42, 3-10 
steroids: molecular mechanisms. Trends Pharmacol Sci 1993; 14: 436-441.

58 Barnes PJ. A new approach to asthma therapy. $N$ Engl J Med 1989; 321: 1517-1527.

59 Barnes PJ. Inhaled glucocorticoids for asthma. $N$ Engl J Med 1995; 332: 868-875.
60 Barnes PJ, Chung KF. Questions about inhaled $\beta_{2}$-agonists in asthma. Trends Pharmacol Sci 1992; 13: 20-23.

61 Haahtela T, Järvinsen M, Kava T, et al. Effects of reducing or discontinuing inhaled budesonide in patients with mild asthma. $N$ Engl J Med 1994; 331: 700-705. 